\title{
Structure of Nanocrystals in Finemets with Different Silicon Content and Stress-Induced Magnetic Anisotropy
}

\author{
Nikolay V. Ershov ${ }^{1}$ and Yuri P. Chernenkov2 ${ }^{2 *}$ \\ ${ }^{1}$ Institute of Metal Physics, Ural Branch of Russian Academy of Sciences \\ 2B.P.Konstantinov Petersburg Nuclear Physics Institute, Russian Academy of Sciences \\ Russian Federation
}

\section{Introduction}

Nanocrystalline Fe-Si-B-Nb-Cu alloys (Finemets) obtained by crystallization of amorphous ribbons quenched from the melt exhibit high soft magnetic properties: the permeability greater than $10^{5}$, coercive force of about $0.002 \mathrm{Oe}$ and the saturation magnetization exceeding $10 \mathrm{kGs}$ (Yoshizawa et al., 1988). In addition, their permeability can be purposefully controlled by inducing a magnetic anisotropy during annealing in a magnetic field (Herzer, 1992; Yoshizawa \& Yamauchi, 1989) or in the field of tensile stress (Glazer et al., 1991; Herzer, 1994; Hofmann \& Kronmüller, 1996). Magnetic anisotropy energy exceeding $5000 \mathrm{~J} / \mathrm{m}^{3}$ is attained by annealing under a tensile stress of $400-600 \mathrm{MPa}$. For the first time the effect of tensile load applied along the ribbon at nanocrystallization annealing was investigated in (Glazer et al., 1991) and it was shown that after such treatment in a sample of the alloy $\mathrm{Fe}_{73.5} \mathrm{Si}_{13.5} \mathrm{~B}_{9} \mathrm{Nb}_{3} \mathrm{Cu}_{1}$ a state with the magnetic anisotropy of the "easyplane" type is formed. The plane of the magnetic anisotropy is oriented perpendicularly to the direction of stretching. For the first time it was assumed that the transverse magnetic anisotropy is due to residual elastic strain in the lattice of nanocrystals having a negative constant of the magnetostriction.

It is known that the type of the magnetic anisotropy induced in the $\mathrm{Fe}_{87-X} \mathrm{Si}_{X} \mathrm{~B}_{9} \mathrm{Nb}_{3} \mathrm{Cu}_{1}$ alloy during tensile stress annealing (TSA) depends on the silicon content $X$ (Serikov et al., 2006). If $X \leq 8$, in specimens after TSA the magnetic anisotropy of easy axis type is induced, whose axis is oriented along the tape (i.e. in the direction of load application during TSA). In the process of reversal magnetization along the tape axis, the permeability and the residual magnetization increase, coercive force decreases, the hysteresis loop becomes rectangular. If the concentration of silicon is equal to or greater than 11 at.\%, then a transverse magnetic anisotropy of easy-plane type is formed after TSA. In this case, the permeability is constant over a wide range of magnetic fields (up to $125 \mathrm{Oe}$ ), the magnetic hysteresis loop becomes inclined, and the magnetization is oriented predominantly in a plane perpendicular to the direction of load application during the annealing.

\footnotetext{
* Vladimir I. Fedorov², Vera A. Lukshina ${ }^{1}$, Nadezda M. Kleinerman¹, Vadim V. Serikov'1, Anatoly P. Potapov ${ }^{1}$ and Nikita K. Yurchenko ${ }^{2}$
} 
If the formation of a state with magnetic anisotropy after annealing and cooling under a tensile load is associated with residual elastic stresses (Glazer et al. 1991; Herzer, 1994), - a result of the so-called Villari effect, then the type of magnetic anisotropy can be explained by the nature of magnetoelastic interactions in the nanoparticles (Serikov et al., 2006; Filippov, 2006) mainly consisting of Fe-Si crystals having a bcc lattice. This argument is supported by the fact that, in bulk crystalline samples of the $\mathrm{Fe}_{1-\mathrm{x}} \mathrm{Si}_{\mathrm{x}}$ alloy, with increasing concentration of silicon the magnetostriction constant changes its sign from positive to negative at $\mathrm{x} \sim 0.12$ (Bozorth, 1993; Bertotti \& Fiorillo, 1994c), and that the silicon concentration in nanoparticles is a few percent higher then the average Si concentration $X$ in the alloy (Serikov et al., 2006). For example, if $X$ is equal to 8 at.\% then silicon in nanocrystals is contained in an amount of about 12 at. $\%$.

In the $\mathrm{Fe}_{73.5} \mathrm{Si}_{15.5} \mathrm{~B}_{7} \mathrm{Nb}_{3} \mathrm{Cu}_{1}$ alloy after TSA, residual deformations of a bcc nanocrystal lattice were detected by $\mathrm{X}$-ray diffraction analysis judging from the shifts of one Bragg reflection (Ohnuma et al., 2003, 2005). In these papers it has been shown that the crystal lattice is stretched in the direction of load application and is compressed in the transverse direction, the strain and the magnetic anisotropy energy being proportional to the load.

Detailed studies of the residual strains have shown that deformations of the bcc lattice of FeSi nanocrystals are not isotropic: extension and compression along the $<100>$ directions are maximum, and in the <111 $>$ - are minimum (Chernenkov et al., 2010). Therefore, the formation of a state with transverse magnetic anisotropy in the nanocrystals of the $\mathrm{Fe}_{73.5} \mathrm{Si}_{13.5} \mathrm{~B}_{9} \mathrm{Nb}_{3} \mathrm{Cu}_{1}$ alloy, which is characterized by the orientation of magnetic moments transverse to the direction of stretching, is due to the negative magnetoelastic coupling that is caused by residual anisotropic lattice deformations of the Fe-Si nanocrystals with a large fraction of the $\mathrm{Fe}_{3} \mathrm{Si}$ phase. The research presented was undertaken to ascertain in detail the atomic structure of nanocrystals of Fe-Si-B-Nb-Cu alloys, depending on the silicon content and the thermal treatment of the samples.

\section{Nanocrystalline Fe-Si-B-Nb-Cu alloys and their magnetic properties}

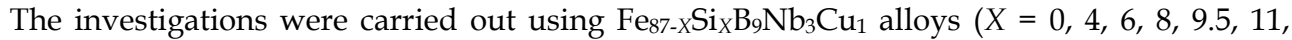
13.5) on samples in the form of ribbons $20 \mathrm{mcm}$ thick and $1 \mathrm{~mm}$ wide obtained in the initial amorphous state by melt-spinning technique, where a molten metal alloy is ejected through an orifice onto a rotating copper wheel. The nanocrystallization annealing (NCA) and the stress annealing (TSA) under a tensile stress of $440 \mathrm{MPa}$ were carried out in air at a temperature of $520^{\circ} \mathrm{C}$ for 120 minutes (under these conditions, no secondary recrystallization still occurs and coercive force shows up no sharp changes in the annealingtemperature range of $510-570^{\circ} \mathrm{C}$ ).

As a result of the heat treatments, samples from the alloys in three different states: initial (or immediately after quenching on the wheel), nanocrystalline (after NCA) and subjected to TSA were obtained. The magnetic state of the samples after NCA and TSA was controlled by the shape of hysteresis loops measured by the ballistic method using an F-190 microwebermeter (Serikov et al., 2006). The hysteresis loops of the samples after NCA and TSA treatments measured upon reversal magnetization along the ribbon are compared in Fig. 1. It is seen that with increasing silicon content $X$ from 0 to 13.5 the samples subjected to NCA show a decrease in the saturation magnetization $B_{s}$ from 14.5 to $12.5 \mathrm{kGs}$; the coercive force $\mathrm{H}_{\mathrm{c}}$ decrease from 1.2 Oe at $X=0$ to 0.006 Oe at $X=13.5$ (the data for all compositions are given in Table 1). After TSA, the coercive force decreases only for the alloy without 
silicon $(X=0)$. The greatest changes after TSA are observed in the shape of the hysteresis loops, and the character of changes strongly depends on the silicon content.
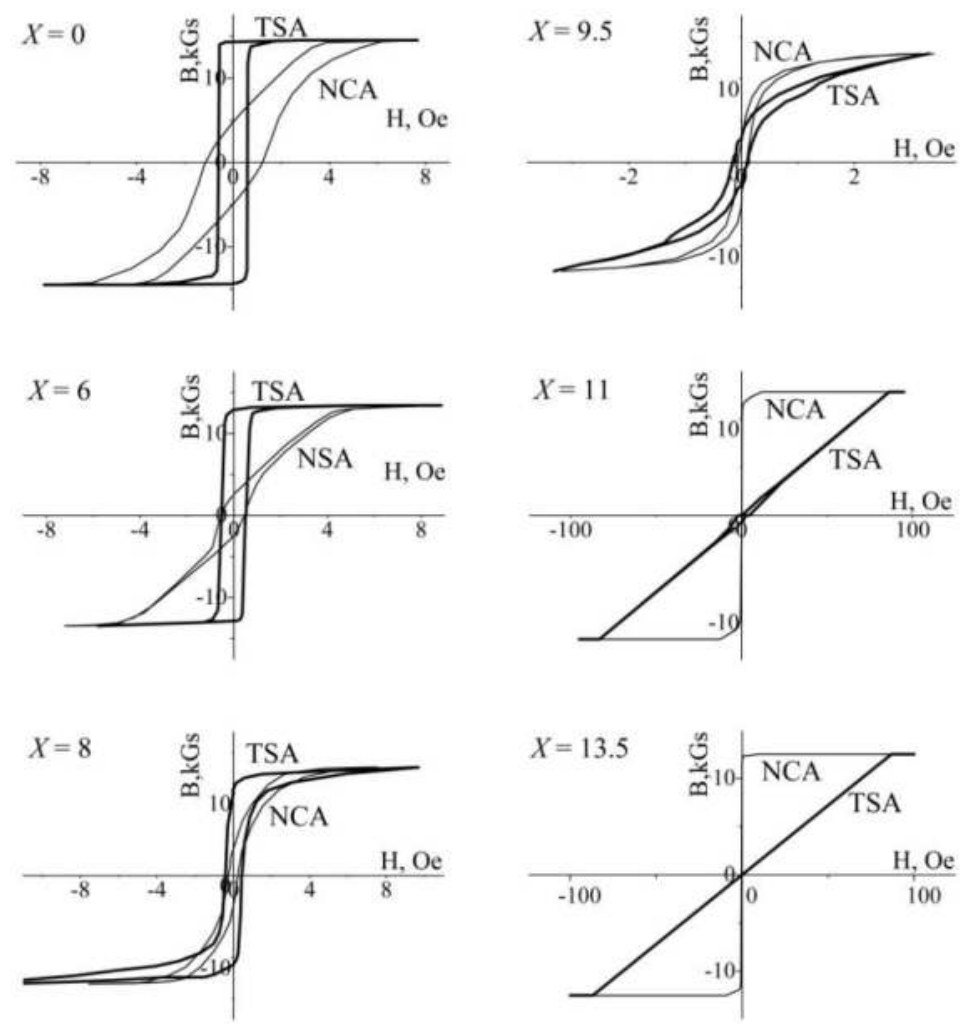

Fig. 1. Hysteresis loops measured for nanocrystalline $\mathrm{Fe}_{87-X} \mathrm{Si}_{X} \mathrm{~B}_{9} \mathrm{Nb}_{3} \mathrm{Cu}_{1}$ alloy after the nanocrystallization annealing (NCA) and tensile stress annealing (TSA).

For samples after TSA with $X<8$, the hysteresis loop shape transforms from inclined into rectangular, with a high magnitude of the remanent magnetization. This indicates the inducing the longitudinal magnetic anisotropy (Fig. 1, $X=0$ and 6). For samples with $X=8$, the loop after the TSA is still steeper than after NCA, and the difference in the slope of the loops is much less than at a lower silicon content. When $X=9.5$, the loops of samples after NCA and TSA are also close to each other, but the loop of sample after TSA is lower than for sample after the NCA, i.e., remanent magnetization decreases as a result of TSA. For samples with $X>9.5$ after TSA treatment, the loops become inclined. This indicates the appearance of a transverse magnetic anisotropy. The sample with $X=13.5$ after TSA has a constant magnetic permeability in the range of magnetic fields from -85 to $85 \mathrm{Oe}$, and its hysteresis loop has an inclined shape.

The magnetic properties of the nanocrystalline $\mathrm{Fe}_{87-\mathrm{X}} \mathrm{Si}_{X} \mathrm{~B}_{9} \mathrm{Nb}_{3} \mathrm{Cu}_{1}$ alloys are controlled by the alloy composition, atomic structure and annealing conditions (Yoshizawa, 2006; Potapov \& Filippov, 2009). 


\begin{tabular}{|c|c|c|c|c|c|c|}
\hline \multirow{2}{*}{ Parameters } & \multicolumn{7}{|c|}{$X$} \\
\cline { 2 - 7 } & 0.0 & 6.0 & 8.0 & 9.5 & 11.0 & 13.5 \\
\hline $\mathrm{B}_{\mathrm{s},}, \mathrm{kGs}$ & 14.5 & 13.45 & 13.2 & 13.0 & 12.8 & 12.5 \\
\hline $\mathrm{H}_{\mathrm{c}}, \mathrm{Oe}$ & 1.2 & 0.5 & 0.25 & 0.075 & 0.049 & 0.006 \\
\hline
\end{tabular}

Table 1. Saturation magnetization, $\mathrm{B}_{\mathrm{s}}$, and coercive force, $\mathrm{H}_{\mathrm{c}}$, depending on silicon content, $X$, in the nanocrystalline alloy $\mathrm{Fe}_{87-X} \mathrm{Si}_{X} \mathrm{~B}_{9} \mathrm{Nb}_{3} \mathrm{Cu}_{1}$.

\section{Nanocrystal structure}

\subsection{X-ray diffraction analysis}

The X-ray diffraction patterns of $\mathrm{Fe}_{87-X} \mathrm{Si}_{X} \mathrm{~B}_{9} \mathrm{Nb}_{3} \mathrm{Cu}_{1}$ alloys were measured in transmission geometry using a four-circle diffractometer and monochromated Mo $K_{\alpha}$ radiation $(\lambda=0.71 \AA)$. The experimental scheme is shown in Fig. 2.

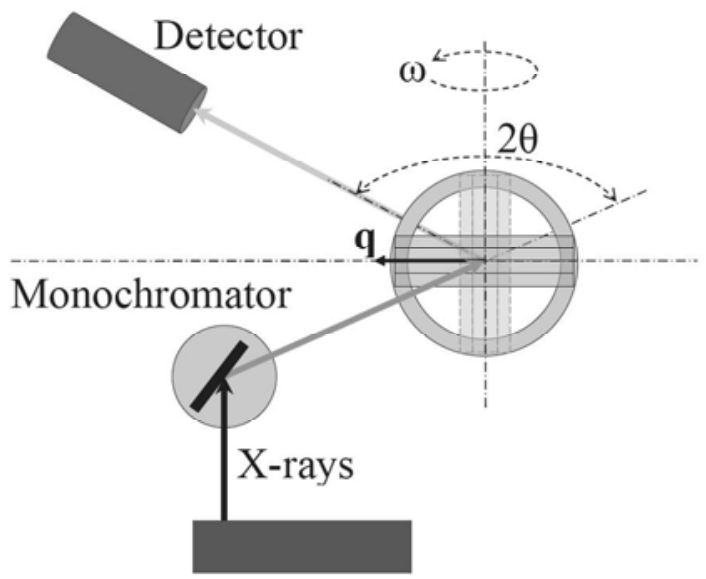

Fig. 2. Scheme of X-ray diffraction experiment. Upon $\theta-2 \theta$ scanning $(\omega=\theta)$, the scattering vector $\mathbf{q}$ lies in the plane of the sample, which has the shape of a rectangular plate. The longitudinal scan corresponds to the orientation of the rectangular plate (solid lines), when the scattering vector $\mathbf{q}$ is parallel to the ribbons. In the transverse scan (orientation of the plate is shown by the dashed line) the scattering vector is perpendicular to the ribbon axis.

The samples in the form of a rectangular plate were prepared from ribbon fragments, which were glued to the thin narrow ring-like holder parallel to each other in several overlapping layers of thickness about $40 \mathrm{mcm}$. During the $\theta-2 \theta$ scanning, when $\omega$ angle is equal to $\theta$, the scattering vector $\mathbf{q}$ was in the sample plane. The $\omega$ angle is equal to zero, when a sample plate is perpendicular to the direction of the incident X-ray beam. By rotating the sample around the horizontal axis by $90^{\circ}$, the transition from the longitudinal scan, when the scattering vector is directed along the axis of the ribbons, to the transverse scan was carried out. In the case of the samples annealed under stress at the longitudinal scan the scattering vector was parallel to the direction of the tensile load application and perpendicular to it in the transverse scan. For each sample, the diffraction patterns were measured for two orientations, i.e. in the form of longitudinal and transverse scans. 


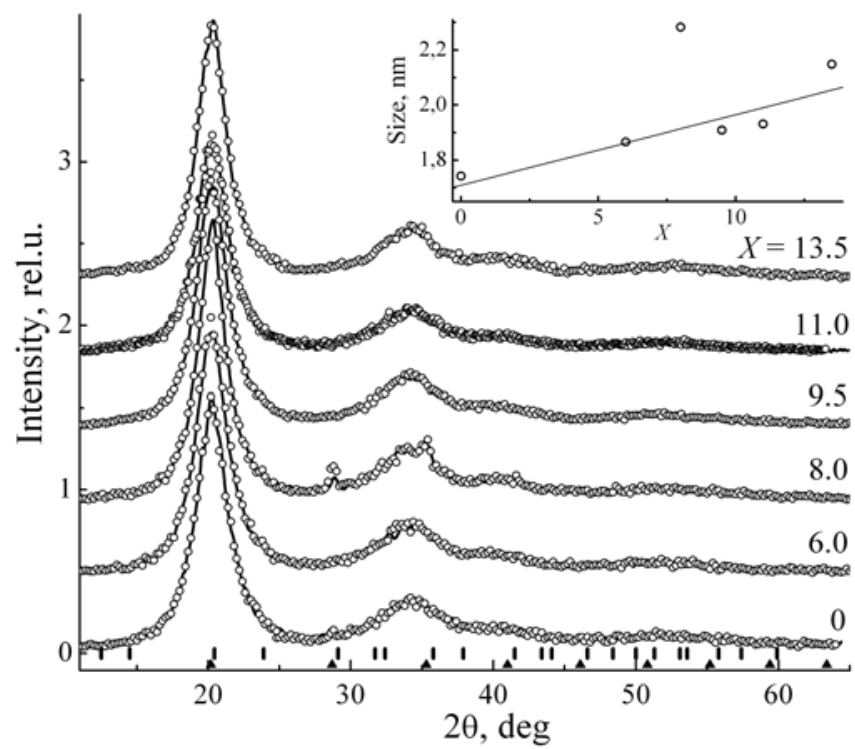

Fig. 3. Diffraction patterns of $\mathrm{Fe}_{87-\mathrm{X}} \mathrm{Cu}_{1} \mathrm{Nb}_{3} \mathrm{Si}_{X} \mathrm{~B}_{9}$ alloys in the initial state measured in the longitudinal (solid line) and transverse (circles) scans. The calculated positions of the peaks for the bcc structure of a-Fe(Si) - $\mathbf{\Lambda}$, and for $\mathrm{Fe}_{3} \mathrm{Si}$ phase - I. The inset shows the dependence of the average size of the regions with a short-range order on $X$.

The X-ray diffraction patterns of $\mathrm{Fe}_{87-X} \mathrm{Cu}_{1} \mathrm{Nb}_{3} \mathrm{Si}_{X} \mathrm{~B}_{9}(X=0,6,8,9.5,11,13.5)$ alloy samples in the initial state are shown in Fig. 3. Within the accuracy of measurements the longitudinal and transverse scans for the same sample are identical. All these diffraction patterns have a shape typical of the quasi-amorphous material (Yoshizawa et al., 1988; Noskova et al., 1992). However, the position of the first peak $\left(2 \theta \approx 20^{\circ}\right)$ coinciding with the Bragg reflection (110) for the bcc structure of iron gives reason to suppose that in the initial state in the alloys there are the regions with bcc short-range order in the arrangement of atoms. Since the iron atoms are a major component of the alloy and the shortest distance between two atoms in the a-Fe is $2.48 \AA$, then the position of the main peak in the diffraction pattern of disordered (amorphous) state can be estimated as $2 \theta_{\text {amorphous }}=16.46^{\circ}$ (Fischer et al., 2006).

Here and below, to describe the shape of reflections, the pseudo-Voigt function defined as a linear combination of Lorentzian and Gaussian with the same halfwidth (FWHM) was selected. After correction for instrumental resolution, integral width of the reflexion was computed, and the average diameter of the bcc grains was calculated by Scherrer formula (Warren, 1969). The dependence of the average sizes of the regions with the bcc order in the atomic arrangement on the silicon concentration is shown in the inset in Fig. 3. Therefore, the structure of the alloy in the initial state can be defined as a fine grained, highly defective bcc structure with the grain sizes about $2 \mathrm{~nm}$. This statement is supported by the fact that the broad diffuse maxima are located close to the calculated positions for the bcc reflections, which are shown in Fig. 3 by triangles. The average size of the ordered regions that contribute to the main peak in the diffraction patterns slightly depends on the concentration of silicon $X$. One point at $X=8$ drops out of a linear dependence, which is apparently due to 
a significant number of relatively large, micron-sized grains of iron that give the narrow Bragg peaks (200) and (211) and narrow and intense contribution to the main peak (110) in the diffraction pattern. Previously, a minor amount of such iron grains was observed in the nanocrystalline samples with $X=0$ and 8 by TEM (Lukshina et al., 2002).

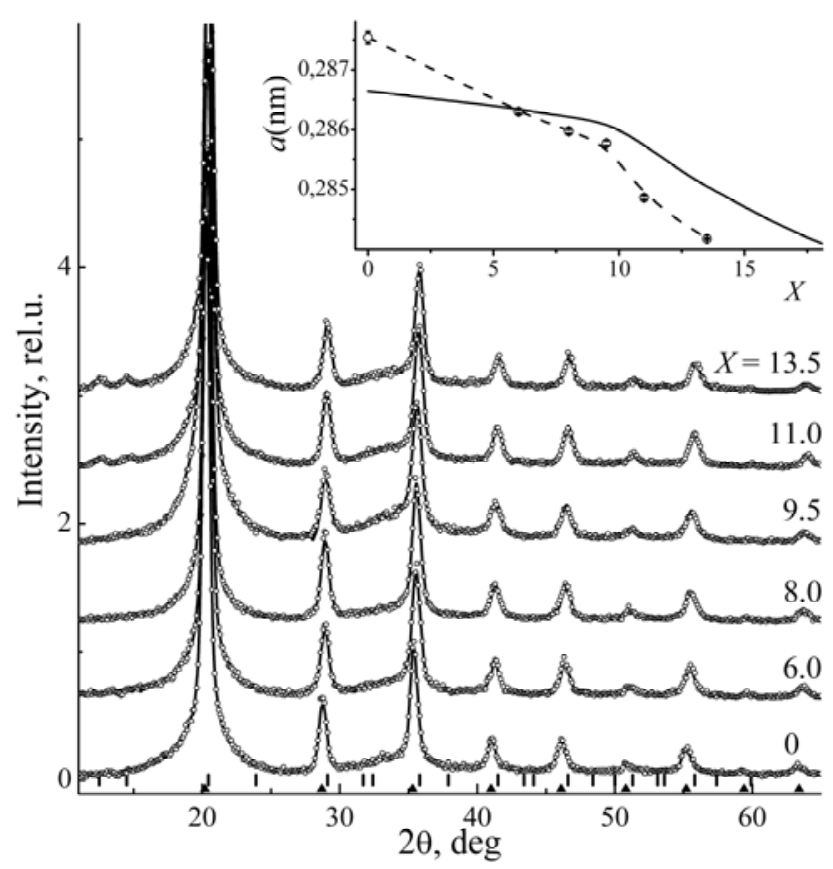

Fig. 4. The same as in Fig. 3, but for samples after the nanocrystallization annealing. The inset shows the dependence of the lattice parameter on the silicon content in the crystalline alloy Fe-Si (solid line) (Bertotti \& Fiorillo, 1994a), and in the Fe(Si) nanocrystals (circles fitted by the dashed line) according to our data.

In the diffraction patterns of the $\mathrm{Fe}_{87-\mathrm{X}} \mathrm{Si}_{X} \mathrm{~B}_{9} \mathrm{Nb}_{3} \mathrm{Cu}_{1}$ alloy samples subjected to NCA shown in Fig. 4, there are peaks with the Miller indices (110), (200), (211), (220), (310), (222), (321), and (330) allowed for the bcc lattice of a-Fe(Si). Whereas the intensity of these reflections is sufficient for quantitative analysis, the intensity of other reflections is too small for it. The unit cell parameter of the ordered $\mathrm{Fe}_{3} \mathrm{Si}$ phase (structure of $\mathrm{D}_{3}$ type) is about twice as high as that of the bcc $\mathrm{Fe}(\mathrm{Si})$ phase. Hereafter we will use the peak indexing for the bcc lattice. Therefore, when the $\mathrm{Fe}_{3} \mathrm{Si}$ phase appears in a sufficient quantity, the superstructure peaks with half-integer indices, e.g. $(1 / 21 / 21 / 2),\left(1^{1 / 2} \frac{1}{1 / 2} 1 / 2\right),\left(1^{1 / 2} 1^{1 \frac{1}{2}} 1 / 2\right)$, etc., as well as the peaks with an odd sum of integer indices $(h+k+l)$, for example (100), (111), (210), etc. should appear. With the available resolution of the diffractometer, the bcc peaks $(h k l)$ of a-Fe $(\mathrm{Si})$ phase in the diffraction patterns coincide with the $\mathrm{D}_{3}$-peaks $(2 h 2 k 2 l)$ of the $\mathrm{Fe}_{3} \mathrm{Si}$ phase.

After annealing at temperature $520^{\circ} \mathrm{C}$ (NCA treatment), the nanocrystals of a-Fe(FeSi) have appeared in all the alloys, independently of the silicon concentration. The average size of the nanocrystals is $10-12 \mathrm{~nm}$. 
The intensity of Bragg reflections at higher angles is rather weak. With increasing silicon content $(X)$ in the samples, and, as a consequence, in the nanocrystals, the Bragg peaks are slightly shifted to the higher angles. It means that the bcc unit cell parameter decreases as in the bulk Fe-Si single crystals (Bozorth, 1993; Bertotti \& Fiorillo, 1994a). The dependencies of the unit cell parameter on $X$ in nancrystals and in bulk samples shown in the inset in Fig. 4 are very similar. A sharper decline in the curve $a(X)$ for nancrystals is probably due to the higher concentration of silicon in nanocrystals than that $\left(\mathrm{C}_{\mathrm{Si}}=X / 100\right)$ in bulk Fe-Si crystal.

A large value of $a(X)$ for alloy with $X=0$ can be explained by the presence in nancrystals of $\mathrm{Nb}$ atoms (atomic radii $0.146 \mathrm{~nm}$ ) substituting for the Fe atoms (atomic radii $0.126 \mathrm{~nm}$ ) in the bcc lattice of iron. With increasing $X$, the $\mathrm{Nb}$ atoms are replaced by $\mathrm{Si}$ atoms (atomic radii $0.118 \mathrm{~nm}$ ), and the unit cell parameter rapidly decreases. A kink in the curve $a(X)$ for Fe-Si crystals at $\mathrm{C}_{\mathrm{Si}}=0.10$ is caused by the formation of the $\mathrm{Fe}_{3} \mathrm{Si}$ phase with the $\mathrm{D0}_{3}$ structure. The $\mathrm{DO}_{3}$ unit cell is composed of eight bcc-unit cells, and its parameter $(0.5652 \mathrm{~nm})$ is less then the doubled unit cell parameter of bcc-Fe $(0.5732 \mathrm{~nm})$. With increasing $X$, the volume fraction of $\mathrm{DO}_{3}$ increases, and the unit cell parameter of the Fe-Si alloy decreases faster $\left(\mathrm{C}_{\mathrm{Si}}>\right.$ $0.10)$ then in the $\mathrm{a}-\mathrm{FeSi}$ phase $\left(\mathrm{C}_{\mathrm{Si}}<0.10\right)$. The similar behaviour of $a(X)$ is observed in the nanocrystals of the $\mathrm{Fe}_{87-\mathrm{X}} \mathrm{Si}_{\mathrm{X}} \mathrm{B}_{9} \mathrm{Nb}_{3} \mathrm{Cu}_{1}$ alloys.

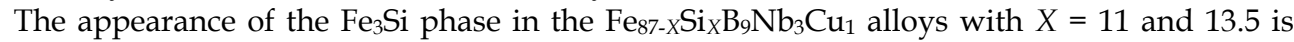
evidenced by two superstructure peaks $\left(1 / 2 \frac{1}{2} \frac{1}{1 / 2}\right)$ and $(100)$ at angles $2 \theta \approx 12$ and $14^{\circ}$ in the diffraction patterns. Other peaks of the $\mathrm{Fe}_{3} \mathrm{Si}$ phase are not distinguishable because they overlap with peaks of a-FeSi phase or their intensity is rather low.

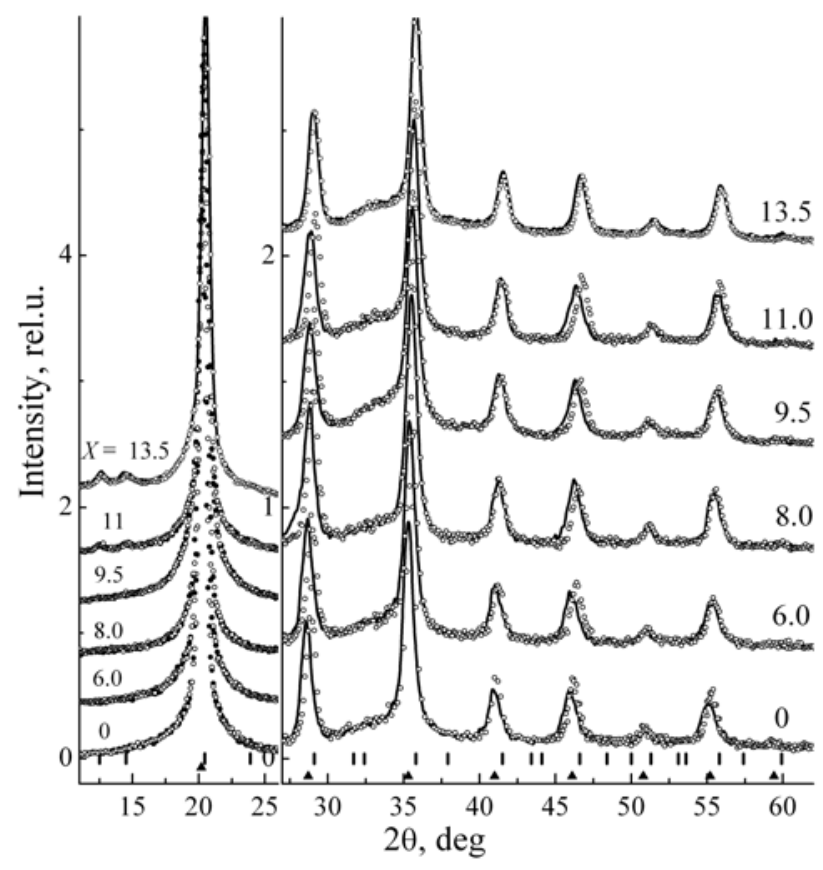

Fig. 5. The same as in Fig. 3 and 4, but for samples after the tensile stress annealing. The scale of intensity in the right part of the figure is two times as large as in the left one. 
The diffraction patterns measured in the longitudinal and transverse scans coincide (Fig. 4). The non-linear background is most probably due to the amorphous matrix surrounding the nanocrystallites in the $\mathrm{Fe}_{87-\mathrm{X}} \mathrm{Si}_{X} \mathrm{~B}_{9} \mathrm{Nb}_{3} \mathrm{Cu}_{1}$ alloy. The phase analysis of the alloy with $X=13.5$ has shown that contributions of $\mathrm{a}-\mathrm{FeSi}(\mathrm{bcc}), \mathrm{Fe}_{3} \mathrm{Si}\left(\mathrm{DO}_{3}\right)$, and amorphous phase (matrix) are comparable (Chernenkov et al., 2010). The number of separate peaks of the $\mathrm{Fe}_{3} \mathrm{Si}$ phase is not enough to obtain the reliable value of the $\mathrm{Fe}_{3} \mathrm{Si}$ fraction, but it is predominant. With decreasing $X$, the $\mathrm{Fe}_{3} \mathrm{Si}$ fraction is reduced, and only a-Fe(Si) nanocrystals and amorphous matrix are retained.

In contrast to the alloys in the initial state and alloys subjected to the nanocrystallization annealing, a shift of peaks is observed in the diffraction patterns from alloys subjected to the tensile stress annealing (Fig. 5).

The diffraction peak profiles measured in the longitudinal and transverse scans for the

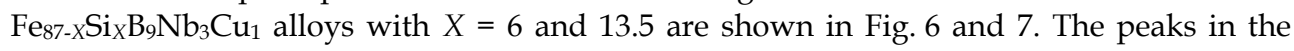
longitudinal scans are shifted to the lower angles. This means that the inerplanar distances in the nanocrystals increase along the direction of the stress application during TSA. The peaks in the transverse scans are shifted in opposite direction, and consequently the inerplanar distances decrease.

The relative shifts of the peaks (Fig. 6 and 7) are different, and correspond to the anisotropic residual deformation of the nanocrystals. The largest shifts are observed for reflections (200) and (310), whereas no shifts are seen for the reflections (222) within the limits of the experimental resolution. The character of shifting the reflections in the diffraction patterns

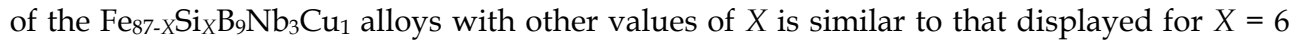
and 13.5 in Fig. 6 and 7.

The anisotropy of the distortion of the nanocrystals can be characterized by the relative change $(\Delta d / d)$ of the interplanar spacing $d$ in their lattice. The positions of all the peaks $(h k l)$ in the diffraction pattern have been determined by the least-square refinement. The peak profile was described by a pseudo-Voigt function, a linear combination of a Lorentzian and a Gaussian of the same full width at half maximum. Each peak was considered to be a sum of two pseudo-Voigt functions corresponding to the contribution of two lines $K_{\mathrm{a} 1}$ and $K_{\mathrm{a} 2}$ in the spectrum of the $\mathrm{MoK}_{\mathrm{a}}$. The value of $\Delta \mathrm{d}$ was determined as a difference between the $\mathrm{d}$ values calculated from the refined positions of the peaks $(h k l)$ in the longitudinal (transverse) scan for the sample subjected to TSA and in the scan for the sample subjected to NCA. As a result of this procedure, relative values of the residual strains of the nanocrystals, $\Delta \mathrm{d} / \mathrm{d}$, were obtained for different directions $[h k l]$ in the lattice, parallel and perpendicular to the direction of the load application during the TSA treatment, independently accounting for the residual lattice extensions and compressions, respectively. Their dependences on the angle $\Phi$ between the direction of the $[h k l]$ vector and the nearest [111] axis are shown in Fig. 8. The residual extensions and compressions change with the silicon content (Fig. 9). The general trend in the $\Delta \mathrm{d} / \mathrm{d}$ dependence on $X$, i.e. the decrease of $\Delta \mathrm{d} / \mathrm{d}$, is in accordance with the enhancement of hardness of the Fe-Si alloys with increasing $\mathrm{C}_{\mathrm{Si}}$ (Bertotti \& Fiorillo, $1994 b)$. Some softening, i.e. an increase of $\Delta d / d$, is observed at $X=11$, where a sharp decrease of the $a(X)$ takes place (Fig. 4). At lower $X$, the values of the relative residual strains, $\Delta \mathrm{d} / \mathrm{d}$, in the longitudinal and transverse directions, in the form of extension and compression of the lattice, respectively, are approximately equal, but at $X=11$ and 13.5, the residual distortions of nanocrystals in the direction of the tensile stress application are about twice as high as in the transverse one (Fig. 9). 

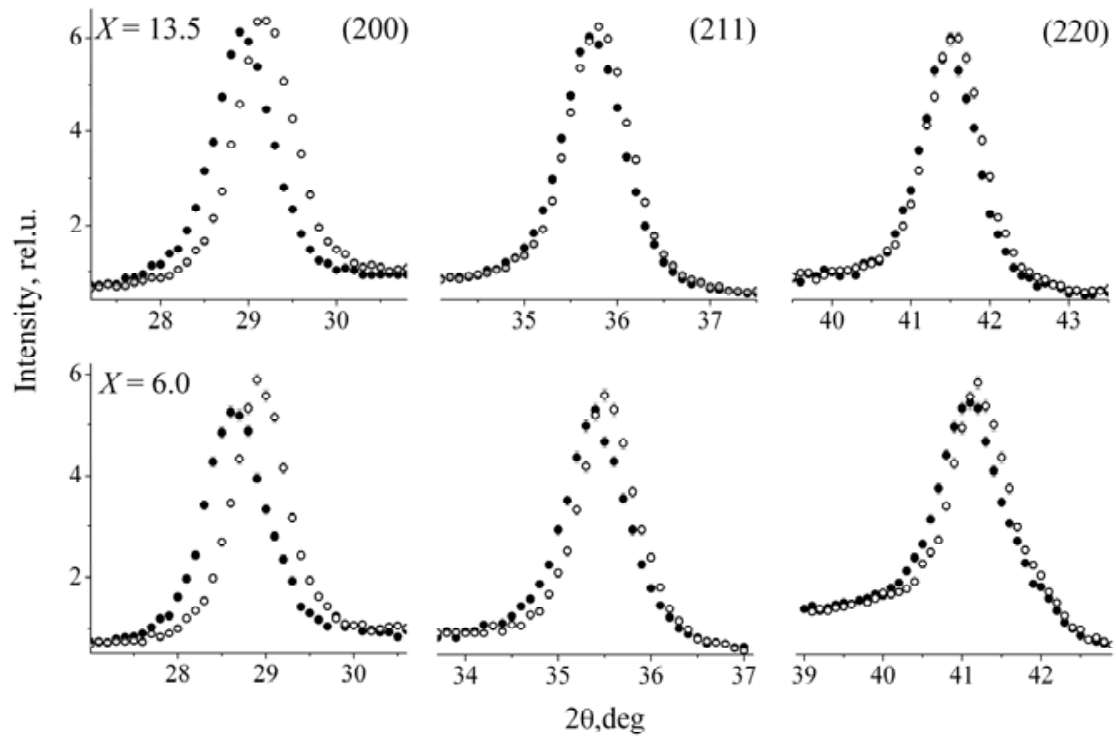

(220)

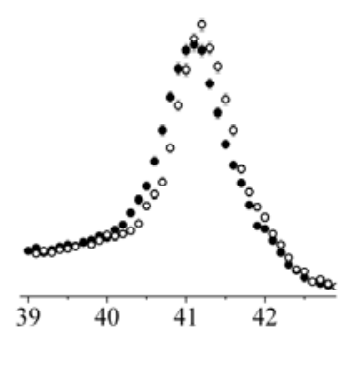

Fig. 6. Profiles of the diffraction peaks (200), (221) and (220) of the $\mathrm{Fe}_{87-X} \mathrm{Si}_{X} \mathrm{~B}_{9} \mathrm{Nb}_{3} \mathrm{Cu}_{1}$ alloy samples at $X=13.5$ and 6 after TSA measured by scanning along $(\bullet)$ and perpendicular $(\circ)$ to the ribbon or the direction of the load application during TSA.

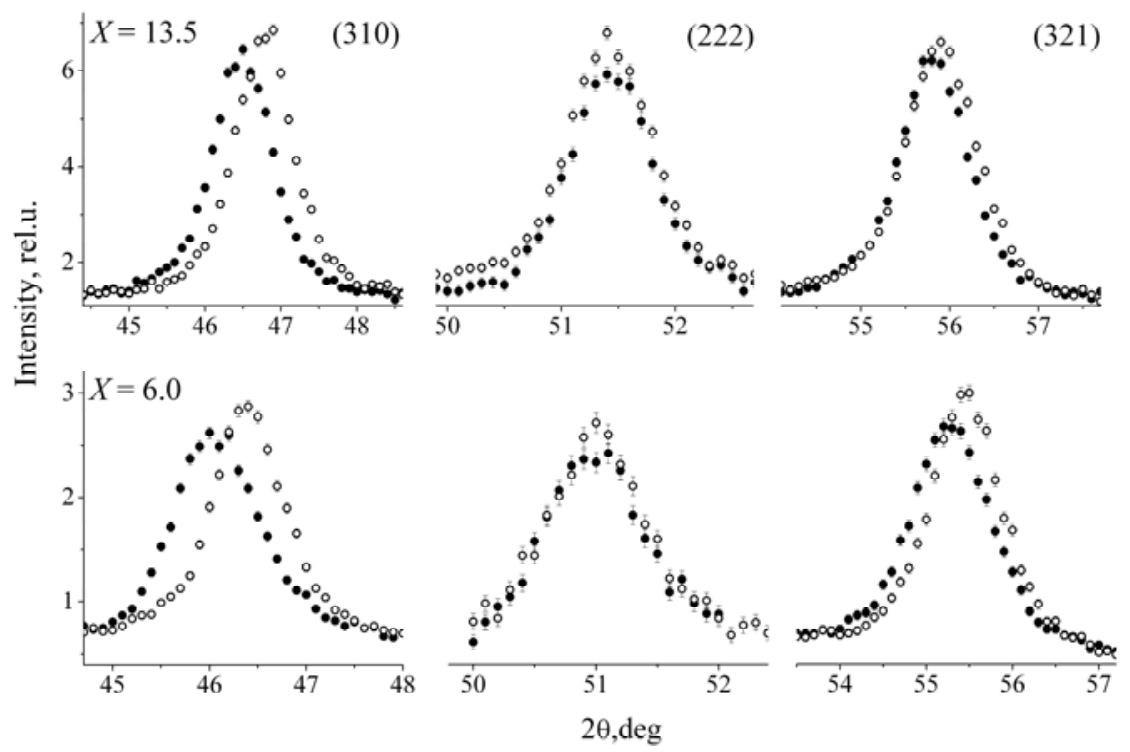

Fig. 7. Profiles of the picks (310), (222) and (321) of the same samples and at the same conditions as in Fig. 6. 


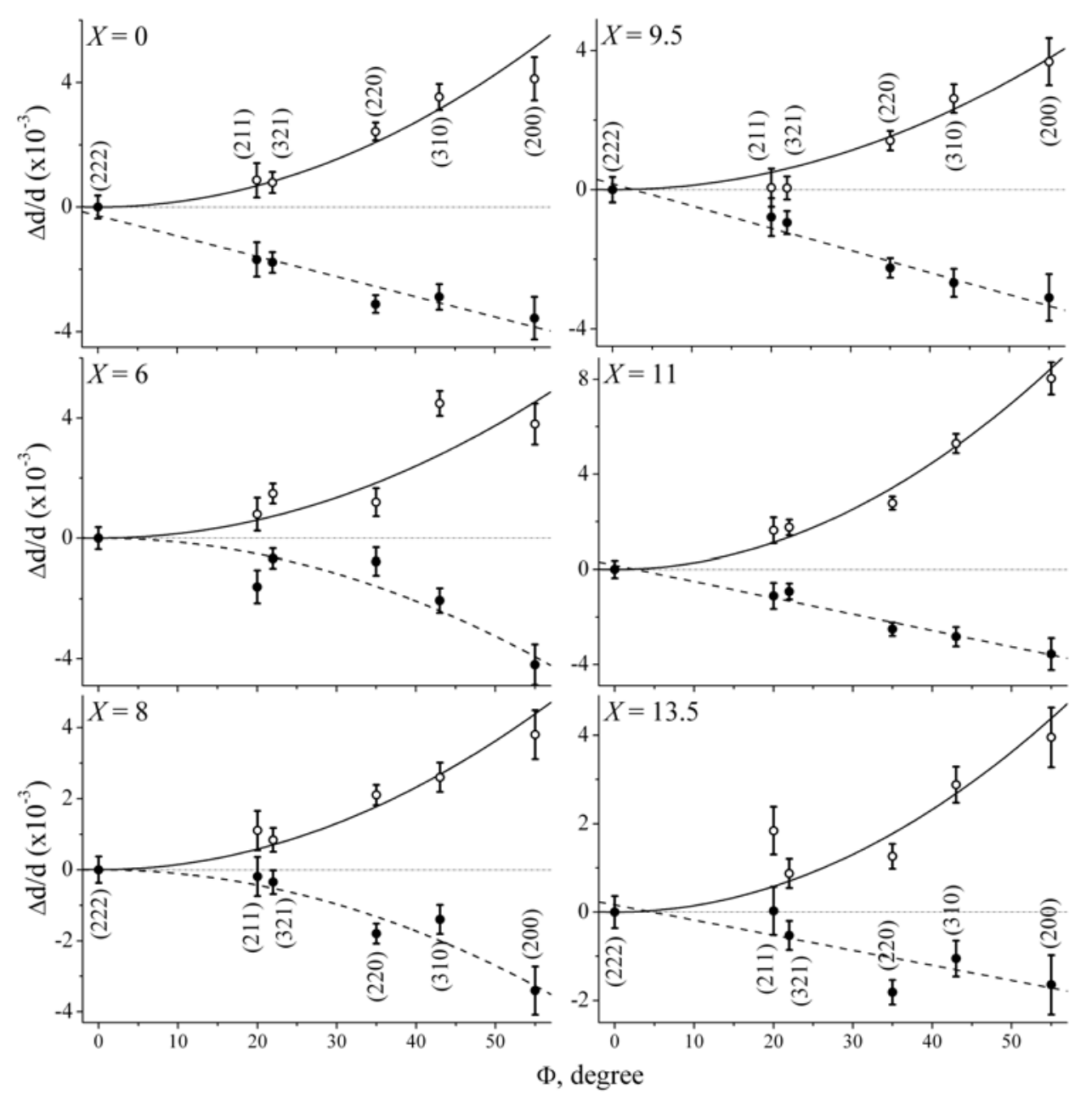

Fig. 8. Relative changes in the interplanar spacing $\Delta d / d$ : longitudinal strains $(\circ)$, and transverse reductions $(\bullet)$ in the alloys with different silicon content $X$ depending on the angle $\Phi$ between the direction $[h k l]$ and the closest axis $<111>$. Lines show the variants of fitting by linear or quadratic functions of the angle.

The distortions of the nanocrystal structure in the $\mathrm{Fe}_{87-X} \mathrm{Si}_{X} \mathrm{~B}_{9} \mathrm{Nb}_{3} \mathrm{Cu}_{1}$ alloy sample subjected to the TSA treatment observed experimentally can be interpreted as follows. In the case of measurements in the transmission geometry, the sample is adjusted so that, during $\theta-2 \theta$ scanning, the scattering vector $\mathbf{q}$ is always in the sample plane. In this case, all the nanocrystals, for which the normals to the $(h k l)$ planes are parallel to the scattering vector $\mathbf{q}_{h k l}$ within the limits of the instrumental resolution, will contribute to the $(h k l)$ reflection in the X-ray diffraction pattern and the position of the maximum in $\theta$ angles $\theta_{h k l}$ will indicate the mean distance between the $(h k l)$ planes in the direction of scanning. 


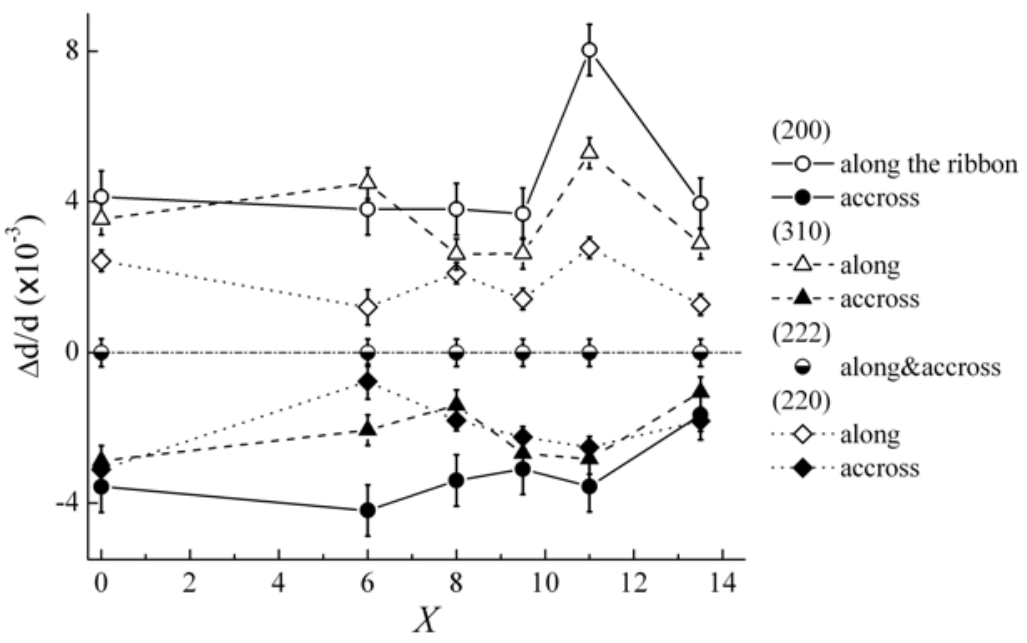

Fig. 9. Dependence of relative extension (along the ribbon) and compression (across the ribbon) of the nanocrystal lattice for the interplanar spacings (200), (220), (310) and (222) on the silicon content $X$.
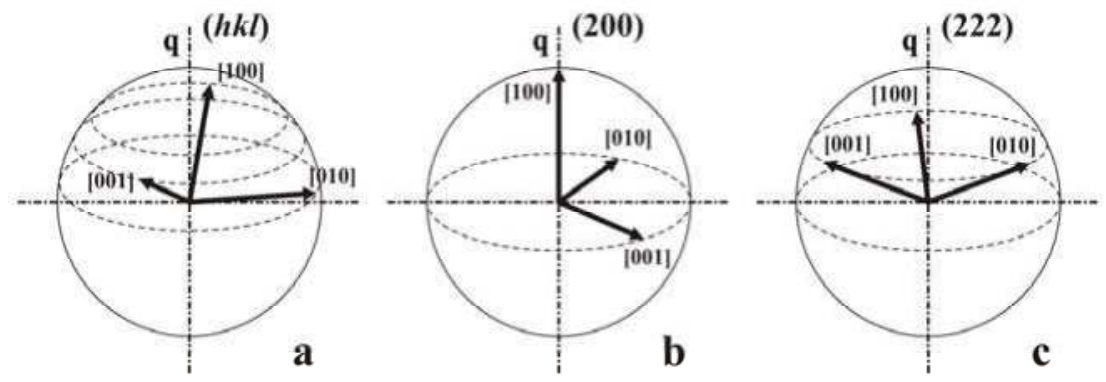

Fig. 10. Orientations of the axes of the nanocrystals contributing to the $(h k l)$ reflection in the $X$-ray diffraction pattern measured during (a) the $\theta-2 \theta$ scanning along the scattering vector $\mathbf{q}$ and (b, c) special cases for the (b) (200) and (c) (222) reflections.

The ends of the $<100>$ crystallographic axes of the set of such nanocrystals on the sphere of a unit radius will circumscribe circles, belonging to the planes normal to the scattering vector q (Fig. 10a). Thus, when scanning along the ribbon, we can trace, from the positions of the $(h k l)$ maxima, changes in the interplanar distances of the nanocrystals, in which corresponding $(h \mathrm{kl})$ planes are normal to the direction of applying the tensile load $\mathbf{P}$ during the TSA treatment (in this case, $\mathbf{q}_{h k l} \| \mathbf{P}$ ). In the case of the transverse scan, the positions of the $(h k l)$ peaks also characterize the distances between the $(h k l)$ planes with the normals oriented crosswise the ribbon or crosswise $\mathbf{P}\left(\mathbf{q}_{h k l} \perp \mathbf{P}\right)$. In the case of the (200) reflection, for which the orientation of the axes is shown in Fig. 10b, the angle $\Phi$ between the normal to the (200) planes parallel to the scattering vector $\mathbf{q}_{200}$ and the [111] direction in the nanocrystals is 
$\sim 55^{\circ}$. The largest distortion of the nanocrystalline lattice is exactly observed along the $<100>$ axis (Figs. 8 and 9; Table 2). Thus, after the TSA treatment, the deformation of the initial cubic unit cell has a tetragonal character: an extension along [100] and contraction along [010] and [001]; the opposite pattern is observed for $\mathbf{q} \perp \mathbf{P}$. The contraction can be explained by displacements of atoms in the bcc lattice during the TSA treatment. If the atoms can be considered as hard spheres, they touch each other in the bcc cell in the directions of the cube diagonals. Their close contact is retained with the extension of the unit cell along [100] if eight atoms in the cube vertices are shifted to the central atom along the diagonals of the $<110>$ cube faces.

\begin{tabular}{|c|c|c|c|c|c|c|c|}
\hline \multirow{2}{*}{$h k l$} & \multirow{2}{*}{$\begin{array}{c}\text { d } \\
\text { degree }\end{array}$} & 0 & 6 & 8 & 9.5 & 11 & 13.5 \\
\hline \multicolumn{7}{|c|}{ along the ribbon - stretching } \\
\hline 200 & 55.0 & $0.41(7)$ & $0.38(7)$ & $0.38(7)$ & $0.37(7)$ & $0.80(7)$ & $0.40(7)$ \\
\hline 211 & 20.0 & $0.08(5)$ & $0.08(5)$ & $0.11(6)$ & $0.00(5)$ & $0.16(5)$ & $0.18(5)$ \\
\hline 220 & 35.0 & $0.24(3)$ & $0.12(5)$ & $0.21(3)$ & $0.14(3)$ & $0.28(3)$ & $0.13(3)$ \\
\hline 310 & 43.0 & $0.35(4)$ & $0.45(4)$ & $0.26(4)$ & $0.26(4)$ & $0.53(4)$ & $0.29(4)$ \\
\hline 222 & 0.0 & $0.00(4)$ & $0.00(4)$ & $0.00(4)$ & $0.00(4)$ & $0.00(4)$ & $0.00(4)$ \\
\hline 321 & 22.0 & $0.08(3)$ & $0.15(3)$ & $0.08(3)$ & $0.05(3)$ & $0.18(3)$ & $0.09(3)$ \\
\hline \multicolumn{7}{|c|}{ across the ribbon - compressing } \\
\hline 200 & 55.0 & $-0.36(7)$ & $-0.42(7)$ & $-0.34(7)$ & $-0.31(7)$ & $-0.36(7)$ & $-0.16(7)$ \\
\hline 211 & 20.0 & $-0.17(6)$ & $-0.16(5)$ & $-0.02(5)$ & $-0.08(5)$ & $-0.11(5)$ & $0.00(5)$ \\
\hline 220 & 35.0 & $-0.31(3)$ & $-0.08(5)$ & $-0.18(3)$ & $-0.22(3)$ & $-0.25(3)$ & $-0.18(3)$ \\
\hline 310 & 43.0 & $-0.29(4)$ & $-0.21(4)$ & $-0.14(4)$ & $-0.27(4)$ & $-0.28(4)$ & $-0.11(4)$ \\
\hline 222 & 0.0 & $0.00(4)$ & $0.00(4)$ & $0.00(4)$ & $0.00(4)$ & $0.00(4)$ & $0.00(4)$ \\
\hline 321 & 22.0 & $-0.18(3)$ & $-0.07(3)$ & $-0.04(3)$ & $-0.09(3)$ & $-0.09(3)$ & $-0.05(3)$ \\
\hline
\end{tabular}

Table 2. The dependence of the relative changes in the interplanar spacing (in the percentage of $\Delta \mathrm{d} / \mathrm{d}$ ) on the angle $(\Phi)$ between the direction $[h k l]$ and the closest axis $<111>$.

The specific case of the orientation of the nanocrystalline axes for the (222) reflection is shown in Fig. 10c. The $<100>$ axes of the nanocrystals that contribute to the (222) reflection are on the cone surface with the apex angle $\sim 55 \times 2^{\circ}=110^{\circ}$, and the angle $\Phi$ is zero. It can be assumed that the absence of the deformation or its minimum value in the [111] direction is provided by a strong interaction of the nearest neighboring atoms arranged along the cube diagonals in the bcc lattice. The interaction hinders an increase in the distances between nearest neighboring atoms during extension. In the case of the tetragonal distortions, the distance between the nearest neighboring atoms is unchanged and only the directions of the bonds between the nearest neighboring atoms are slightly changed.

The residual structure distortions should be discussed using the elastic deformation tensor. However, it is hardly possible to do this, since the available structural information is very limited and the chemical composition of the nanocrystals is likely inhomogeneous: along with $\mathrm{Fe}$ and $\mathrm{Si}$, the composition can also include other atoms. Moreover, the deformed nanocrystals are in the rigid amorphous matrix, in which, after the TSA treatment, residual stresses are likely exist as well. 


\subsection{NGR-spectroscopy}

The local atomic structure, phase composition and orientation of magnetization as a function of silicon content - X were investigated in the alloys after the NCA and TSA by nuclear gamma resonance (NGR, Mössbauer spectroscopy). The Mössbauer spectra were measured on a YaGRS-4M spectrometer in the regime of constant velocity at $20^{\circ} \mathrm{C}$ with a ${ }^{57} \mathrm{Co}$ in a chromium matrix used as the source. From the Mössbauer spectra, the distribution functions of hyperfine fields (HFFs) - P (H) were constructed.

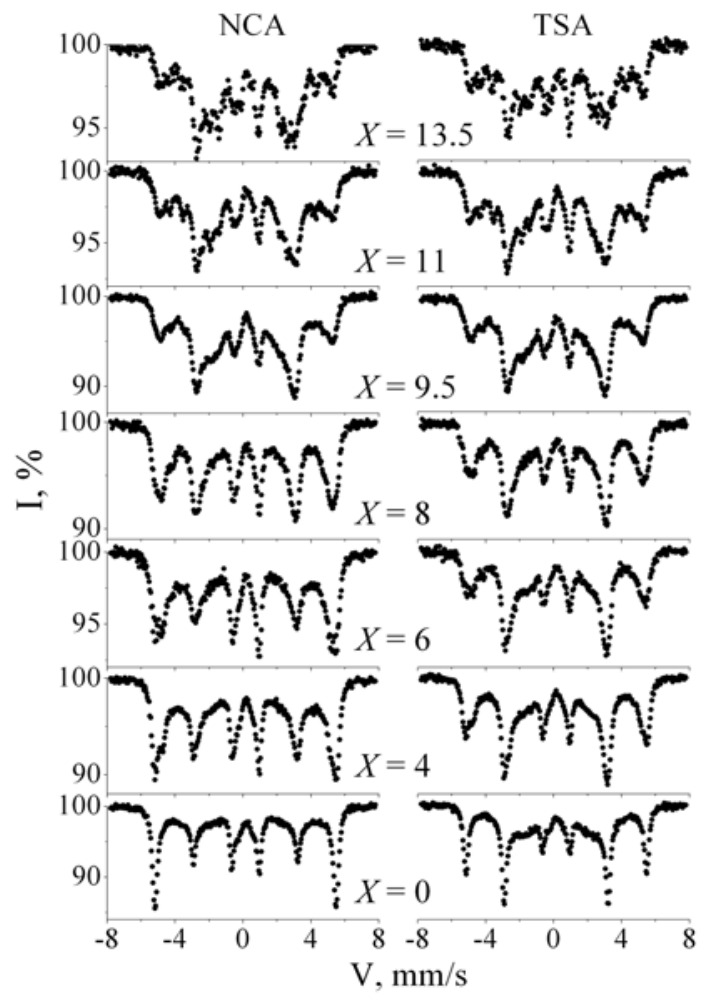

Fig. 11. Mössbauer spectra of the alloys with different values of $X$ after NCA at $520^{\circ} \mathrm{C}$ for 120 minutes and TSA at $520^{\circ} \mathrm{C}$ for 120 minutes under a tensile stress of $440 \mathrm{MPa}$.

Mössbauer spectra of the alloys with different silicon content after the nanocrystallizing annealing and after the annealing under tensile load are shown in Fig. 11. Whereas, the distribution function $\mathrm{P}(\mathrm{H})$, in Fig. 12. The intensity of contributions at fields below $100 \mathrm{kOe}$ is quite small; therefore, this range is not shown here. When analyzing distributions of HFFs, the Mössbauer data on the structure of FeSi alloys (Litvinov et al., 1982; Randrianantoandro et al., 1999; Stearns, 1963) were used.

Based on the Mössbauer spectra, the coefficients that characterize the deviation of the magnetic moments from the sample plane (Wertheim, 1964) were determined as a ratio of intensities of the second (fifth) and first (sixth) lines of the Mössbauer sextet. If the magnetic moment is perpendicular to the sample plane, i.e., lies along the direction of incidence of $\gamma$ 
quanta, then $A_{2} / A_{1}=0$; in the case of an isotropic distribution of the magnetic moment, $\mathrm{A}_{2} / \mathrm{A}_{1}=0.67$; if the magnetic moments are located in the sample plane, $\mathrm{A}_{2} / \mathrm{A}_{1}=1.33$.

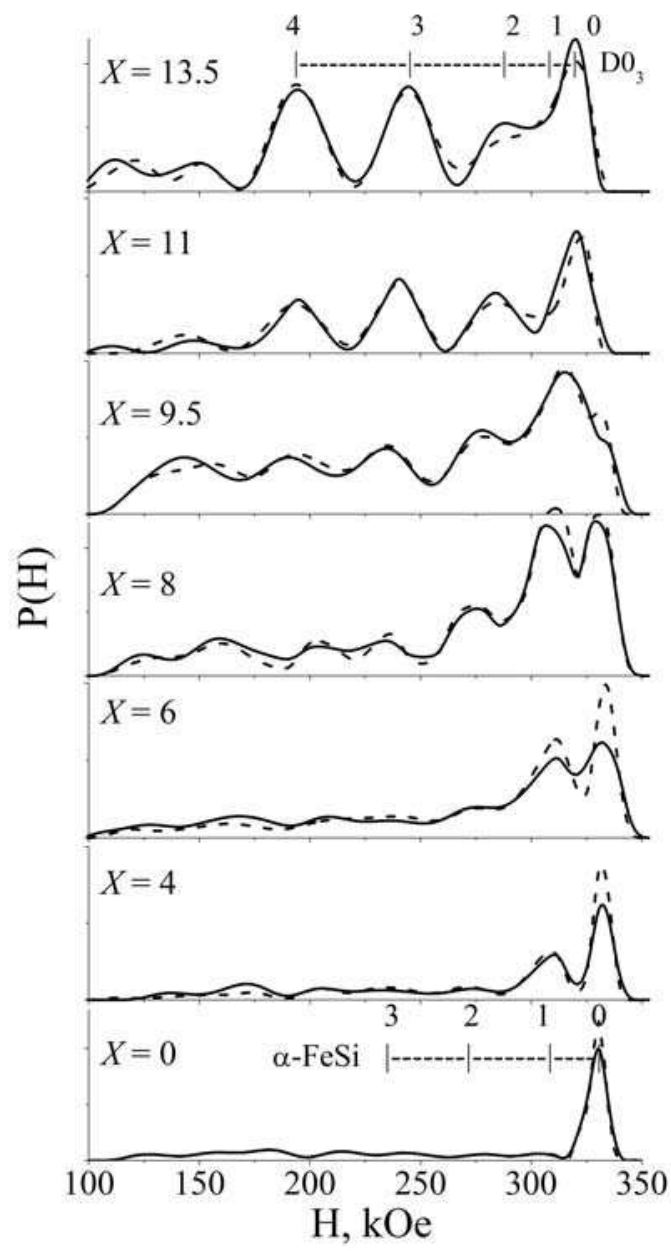

Fig. 12. $\mathrm{P}(\mathrm{H})$, distribution functions of $\mathrm{HFF}$ of the nanocrystalline alloys $\mathrm{Fe}_{87-X} \mathrm{Si}_{X} \mathrm{~B}_{9} \mathrm{Nb}_{3} \mathrm{Cu}_{1}$ with different values of $X$ after NCA (dashed curves) and TSA (solid). With the rulers marked $\mathrm{a}-\mathrm{FeSi}$ and $\mathrm{D}_{3}$ the line positions are shown corresponding to surroundings with 0 , 1,2 , and 3 silicon atoms in the first coordination sphere for the disordered state and to surroundings with $0,1,2,3$ and 4 silicon atoms for the ordered state, respectively.

Fig. 13 displays the concentration dependence of the coefficient $A_{2} / A_{1}$ for the alloys studied, which is compared with the magnitudes of the constant of induced anisotropy, $\mathrm{K}_{\text {TSA, found }}$ from the hysteresis loops measured on the samples subjected to TSA (Serikov et al., 2006). It is seen that in all the curves there is a feature near the Si content $X \sim 8$. In the case of heat treatment without a tensile stress, the magnetic moments are off the sample plane at small 
silicon concentrations, which appears to indicate a strong influence of borides on the iron grains (Kleinerman et al., 2004); a further growth of silicon content leads to the orientation of magnetic moments in the sample plane. After TSA the magnetic moments lie in the sample plane already at small silicon concentrations, but are oriented along the ribbon axis; later, they change the orientation to the transverse and then become somewhat off the sample plane.

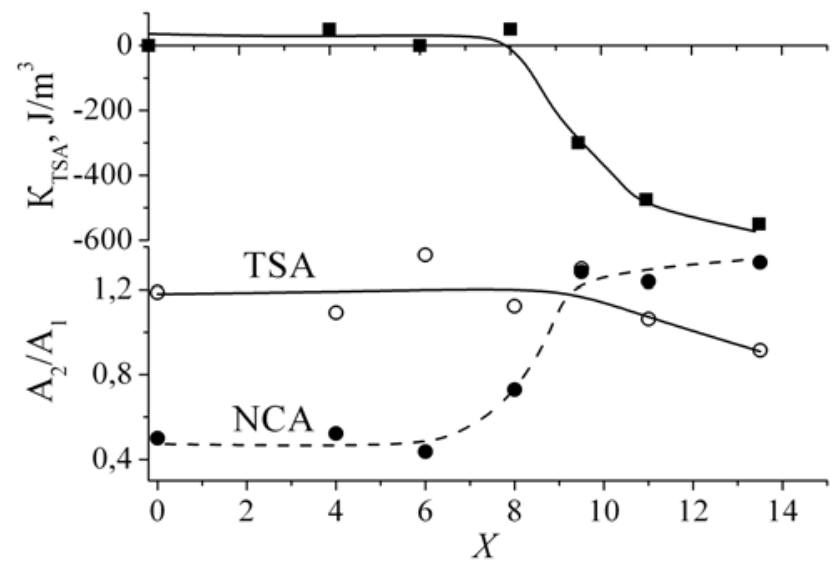

Fig. 13. Variation of the anisotropy constant $K_{T S A}$ and of the ratio $A_{2} / A_{1}$ as functions of the silicon content $X$ for the alloys subjected to NCA $(\bullet)$ and TSA (०).

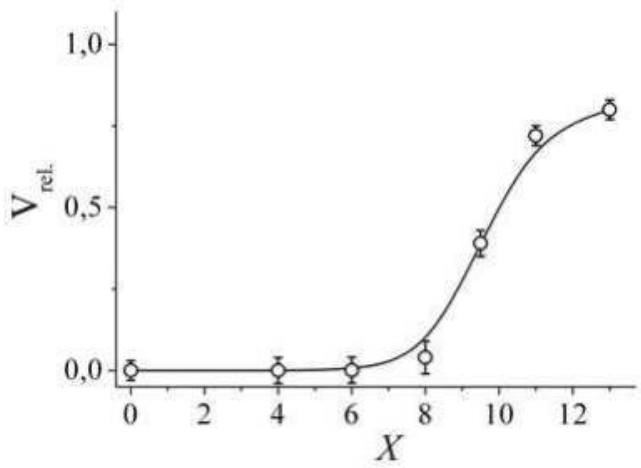

Fig. 14. The relative volume fraction of the ordered phase $\mathrm{Fe}_{3} \mathrm{Si}-\mathrm{V}_{\text {rel }}$ in the nanocrystalline $\mathrm{Fe}_{87-X} \mathrm{Si}_{X} \mathrm{~B}_{9} \mathrm{Nb}_{3} \mathrm{Cu}_{1}$ alloy depending on the average silicon concentration - $X$.

The qualitative analysis of the concentration dependence of the distributions $\mathrm{P}(\mathrm{H})$ shown in Fig. 12 gives the following results. For $X=0$ the distribution function over the local surroundings of iron atoms has a peak at $\mathrm{H}=330 \mathrm{kOe}$ slightly broadened, but coinciding with the line of 8:0 ( $8 \mathrm{Fe}$ atoms and $0 \mathrm{Si}$ atoms in the first coordination shell of the Fe atom) for pure iron. The addition of silicon in the alloy $(X=4$ and 6$)$ leads to a slight growth of the field at the 8:0 peak maximum of the function $\mathrm{P}(\mathrm{H})$. Apparently, the effect of Si atoms in the 
remote (third or fourth) coordination shells of Fe atoms is thus manifested in the change of the hyperfine field at the iron nuclei. In the alloy with $X=9.5$ there is a significant fraction of the structural component of 8:0 type with a field close in value to $330 \mathrm{kOe}$, which almost completely disappears from the $\mathrm{P}(\mathrm{H})$ at $X=11$. When $X$ is in the range between 6 and 9.5, there appears a first sign of the local configuration 4:4, i.e., of four $\mathrm{Si}$ atoms in the first coordination shell of iron, typical of the $\mathrm{D}_{3}$ ordering. Because of the six silicon atoms in the second coordination shell of an iron atom that has only iron in the first shell - a configuration characteristic of the $\mathrm{D}_{3}$ phase, there takes place the decrease of the hyperfine field of the maximum of $\mathrm{P}(\mathrm{H})$ that corresponds to coordination 8:0. When $X=13.5$, more than $80 \%$ of the nanocrystal volume is occupied by clusters of the ordered $\mathrm{D}_{3}$ phase. The concentration dependence of the relative volume fraction of the $\mathrm{D}_{3}$ phase $\mathrm{V}_{\text {rel }}$ shown in Fig. 14 was constructed out using the structural and magnetic parameters from (Yelsukov et al., 1989).

An observed fact that after TSA the peaks of 8:0 and 7:1 coordinations are broader than those after the heat treatment without stresses can be explained by the effect of residual strains $(X=6)$. For alloys with $X \geq 8$, the distribution functions $P(H)$ are identical in the main, but the presence of surroundings with two $(6: 2)$ and three $(5: 3)$ silicon atoms in the first coordination shell of iron atom are indicative of the silicon-concentration heterogeneity of nanocrystals and the low degree of the $\mathrm{D}_{3}$ type order in them.

\section{Residual distortions and magnetic anisotropy}

Thus, it is shown that in the samples subjected to TSA, there is a significant residual distortion of the nanocrystal lattice, the anisotropic character of which does not change when the concentration of silicon $X$ varies in the range from 0 to 13.5. The relative lattice distortion along the $<100>$ axis reaches almost 0.01 , which is more than two orders of magnitude greater than the saturation magnetostriction in crystalline a-FeSi alloys (Bozorth, 1993). Most likely, the residual strain in the a-Fe(Si) nanocrystals is retained owing to rigidity of the surrounding amorphous matrix (Ohnuma et al., 2005).

The formation of the magnetic anisotropy after annealing and cooling under tensile load (TSA treatment) can be attributed to the residual elastic stresses in the alloy nanoparticles (Glaser et al., 1991; Herzer, 1994). Then, the change of the magnetic-anisotropy type from longitudinal to transverse is explained, respectively, by changing the sign of the magnetoelastic coupling in the nanocrystals from positive to negative with increasing the silicon content. The magnetoelastic Villari effect consisting in the change of magnetization in magnetic materials under the influence of mechanical stretching is the inverse phenomenon of the magnetostriction. If at the positive Villari effect, the magnetization along the direction of elongation increases, then at the negative magnetoelastic effects, on the contrary, an elastic elongation leads to a decrease of magnetization. In the bulk a-Fe(Si) crystals with the positive magnetostriction (and the positive Villari effect), the magnetization is predominantly oriented along one of the easy axes $<100>$ forming the smallest angle with the direction of elongation. Upon saturation of the effect, which corresponds to the strain $\sim 20-25 \times 10^{-6}$, almost $100 \%$ of the magnetic moments are directed along this axis. If the magnetoelastic coupling takes up a negative value, as in the ordered $\mathrm{Fe}_{3} \mathrm{Si}$ alloy, the elongation would result in a deviation of the magnetic moments of individual Fe atoms from the longitudinal direction toward the transverse direction. They will be mainly oriented along one of the easy axes $<100>$ that is perpendicular to the direction of the 
elongation or has the smallest angle with the plane transverse to it. The critical point of silicon concentration $\mathrm{C}_{\mathrm{Si}}$, in which the magnetostriction constant changes its sign (see, for example, $\lambda_{100}$ in Fig. 15), is the value of $\mathrm{C}_{\mathrm{Si}} \approx 0.12$ (Bertotti \& Fiorillo, 1994c).

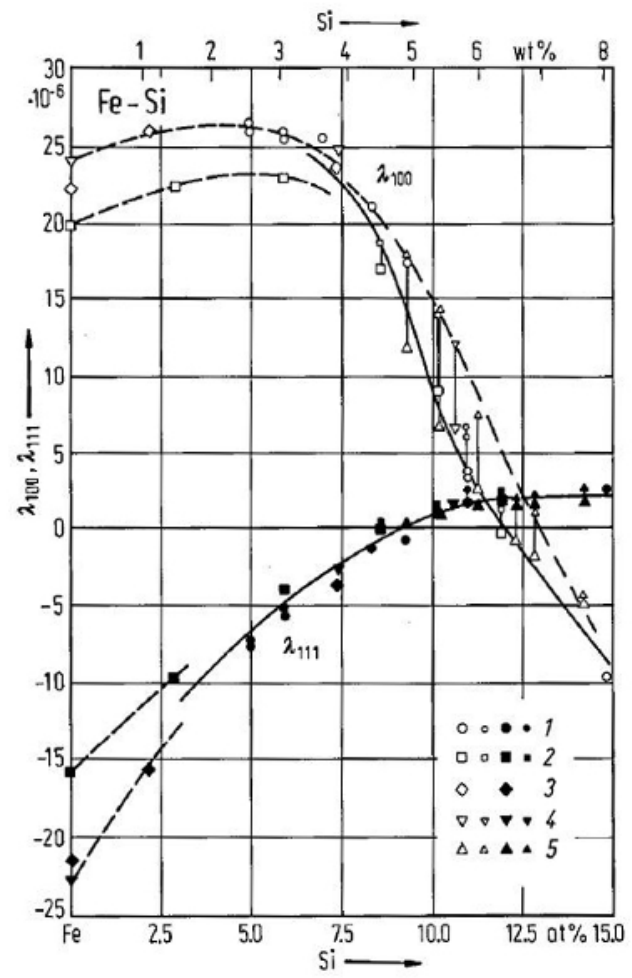

Fig. 15. Magnetostriction constants as functions of Si concentrations, determined by straingauge measurements on single crystals (room temperature). Large symbols: slowly cooled specimens. Small symbols: specimens quenched from temperature of the order of $1000^{\circ} \mathrm{C}$. Image was taken from the database (Bertotti \& Fiorillo, 1994c), Fig. 42.

The dependence of the magnetostriction constant $\lambda_{100}$ on the $C_{S i}$ largely reflects an increase in the volume fraction of the ordered $\mathrm{Fe}_{3} \mathrm{Si}$ phase with increasing concentration of silicon (Hilfrich et al., 1994), which, as known (Bertotti \& Fiorillo, 1994c), has a negative value of the magnetostriction constant $\left(\lambda_{100} \approx-20 \times 10^{-6}, \lambda_{111}=-5 \times 10^{-6}\right)$. With the negative magnetoelastic coupling, which is typical of the ordered $\mathrm{Fe}_{3} \mathrm{Si}$ phase, the relative compression of the lattice should cause an increase in the magnetization along the direction of reduction.

The microstructure of the nanocrystalline $\mathrm{FeSiBNbCu}$ alloy can be represented as a huge number of the isotropically oriented a-Fe (Si) nanocrystals of about $10 \mathrm{~nm}$ in average grain diameter with the bcc lattice, and the clusters of nonmagnetic fcc $\mathrm{Cu}(\mathrm{Fe})$ grains about $5 \mathrm{~nm}$ placed in the residual amorphous matrix phase $\mathrm{Fe}(\mathrm{Nb})-\mathrm{B}$ (Yoshizawa, 2006). The concentration of silicon in the nanoparticles is a few percent higher than its average concentration in the alloy (Serikov et al., 2006). For example, at an average value of $X=13.5$, 
the silicon content in the nanocrystals reaches 18 at.\%. Therefore, if we assume that the magnetoelastic properties of the crystalline Fe-Si alloys can be transferred to the nanocrystalline ones, then the critical point at which the sign of the magnetoelastic coupling changes will be the average silicon concentration $X \approx 9$ in the $\mathrm{Fe}_{87-X} \mathrm{Si}_{X} \mathrm{~B}_{9} \mathrm{Nb}_{3} \mathrm{Cu}_{1}$ alloy.

At this point it should be noted the role of $\mathrm{Fe}_{3} \mathrm{Si}$ phase in the formation of the transverse magnetic anisotropy. The iron-silicon alloy in the ordered $\mathrm{Fe}_{3} \mathrm{Si}$ state ( $\mathrm{D}_{3}$ structure) is characterized by a negative constant of the magnetoelastic coupling. The transverse orientation of the magnetization with respect to the extension direction is characteristic of it, the so-called the transverse Villari effect; and negative magnetostriction - in the magnetic field, the length of the sample in the direction of the field application decreases. Therefore, the transverse magnetic anisotropy induced in the nanocrystalline alloy ribbons after the SA treatment should be attributed to the presence of a substantial fraction of $\mathrm{Fe}_{3} \mathrm{Si}$ phase in the nanocrystals. The presence of $\mathrm{Fe}_{3} \mathrm{Si}$ phase in the nanocrystals grown during NCA or TSA was supported by the following experimental observations. Firstly, as well as in the crystalline a-FeSi alloys the line $a(X)$ (inset in Fig. 4) describing the dependence of the nanocrystal lattice parameter on the silicon concentration has an inflection point at $X \approx 9.5$ associated with the $\mathrm{DO}_{3}$ ordering. Secondly, in the low-angle part of the diffraction patterns

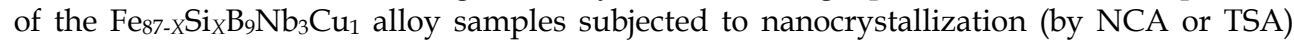
with $X=11$ and 13.5 , there are the superstructure peaks $(1 / 21 / 21 / 2)$ and (100). And finally, the distribution functions $\mathrm{P}(\mathrm{H})$ obtained from the Mössbauer spectra has a weak manifestation of the contribution from the coordination of 4:4 (four Si and four Fe atoms in the first shell of an iron atom) at $X=8$, and a further significant increase of it with $X \geq 9$. The relative volume fraction of $\mathrm{Fe}_{3} \mathrm{Si}$ phase obtained from these data reaches $80 \%$ at $X=13.5$. The observed changes in the phase composition of the nanocrystals depending on the silicon concentration correlate with the magnetic properties (a form of the magnetic hysteresis loops and the magnetic anisotropy constant). When $X \geq 9.5$ the constant $\mathrm{K}_{\mathrm{TSA}}$ is negative and grows in magnitude. Most clearly, the transverse magnetic anisotropy is pronounced in the form of the loops for samples with $X=11$ and 13.5. For the same values of $X$, the magnetization comes from the sample plane as observed after the TSA treatment.

Fig. 16a represents schematically one of the 48 equivalent spherical triangles. The direction of tensile stress application relative to the nanocrystalline axes is shown by the radiusvector for three most interesting cases, namely, along [010], [110], and [111]. We remind that the nanocrystals have random orientation in the $\mathrm{Fe}-\mathrm{Si}-\mathrm{Nb}-\mathrm{Cu}-\mathrm{B}$ alloy and, hence, a random one relative to the ribbon axis. The distortions of the nanocrystal lattice are different for the radius-vectors within this spherical triangle. The nearly tetragonal distortions correspond to the case where the radius-vector is directed along an easy-magnetization $<100>$ axis of a nanocrystal, for example, [010] in Fig. 16a. After TSA in the nanocrystals of the $\mathrm{Fe}_{87-\mathrm{X}} \mathrm{Si}_{X} \mathrm{~B}_{9} \mathrm{Nb}_{3} \mathrm{Cu}_{1}$ alloys with the positive magnetoelastic coupling constant (longitudinal Villari effect) at $X<9$, the magnetization will be oriented along one of the easy axes $<100>$ that makes the smallest angle with the axis of residual strain or with the direction of load application $\mathbf{P}$. In this case the maximum deviation from the longitudinal direction can be $55^{\circ}$ for those nanocrystals that have [111] axis parallel to the direction of tensile load application $\mathbf{P}$. But for this direction the residual distortion is minimum, if any is. If the nanocrystal axis [110] $\| \mathbf{P}$, then the deviation of magnetization from the longitudinal axis of the ribbon will be $45^{\circ}$. The value of the residual strain along the [110] $-\Delta \mathrm{d}_{110} / \mathrm{d}_{110}$ is not more then $1 / 2$ of $\Delta d_{100} / d_{100}$. Since the greatest value of the relative lattice distortion was observed in nanocrystals oriented with one of the axes $\langle 100\rangle$ along $\mathbf{P}$, then the 
magnetization in these nanocrystals is oriented parallel to $\mathbf{P}$, making the largest contribution to the formation of the longitudinal magnetic anisotropy. Since the density of the magnetic anisotropy energy is proportional to the interplanar spacing strain $\Delta d / d$, then the nanocrystals with tetragonal deformation of lattice will give the largest contribution to the energy of the longitudinal magnetic anisotropy, when one of the easy magnetization axes $<100>$ is parallel to the ribbon axis and $\mathbf{P}$.

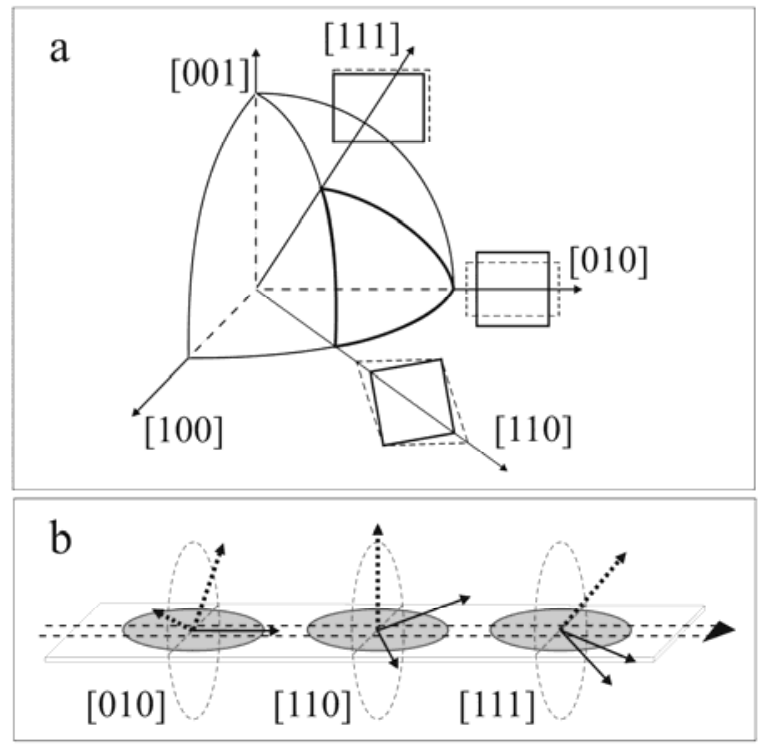

Fig. 16. a - scheme of the distortions of the nanocrystal lattice (dashed lines) for different directions of tensile load application parallel to the radius vectors [111], [010] and [110]. The distortions are shown in projection on (001) plane in the case of extension along [010] and [110], and on the plane (1-1 0) in the case of extension along [111].

$\mathrm{b}$ - the corresponding variants of orientations of the crystallographic axes $<100>$ (straight lines with arrows) and magnetization (dashed lines with arrows) in the nanocrystals with the transverse Villari effect relative to the ribbon axis or the direction of load application double dotted line with an arrow.

For $X>9$, the magnetoelastic coupling in nanocrystals becomes negative (transverse Villari effect). The tetragonal distortions correspond to the case when the radius vector is directed along the easy axis $<100>$ of the nanocrystal in Fig. 16b - [010]. Owing to the transverse Villari effect, the magnetization of these nanocrystals is to be directed with equal probability along either [100] or [001]. The residual distortion along [110] results in the nanocrystal magnetization along [001] as shown in Fig. 16b. The magnetization of the nanocrystals with the axis of $\langle 111>$ type parallel to the ribbon axis (i.e. the tensile stress direction) is to be directed along one of the easy axes $<100>$. Their deviation from the ribbon axis is about $55^{\circ}$. Thus, these nanocrystals also give contribution to the transverse magnetization (Fig. 16b). The radius-vectors $<111>$ and $<100>$ correspond to two limiting cases: the magnetization direction of a nanocrystal makes an angle of $55^{\circ}$ and $90^{\circ}$ with the ribbon axis, and of $35^{\circ}$ and 
$0^{\circ}$ with the transverse plane, respectively. The magnetization directions of all the nanocrystals must lie within $\pm 35^{\circ}$ to the plane normal to $\mathbf{P}$. Taking into account the random orientation of nanocrystals and the anisotropy of lattice strains in the nanocrystals, we can estimate the ratio of the magnetization components that are perpendicular and parallel to the ribbon axis as at least 3 to 1 . The anisotropy of the residual strains facilitates an increase in the transversal component nature of the magnetic anisotropy induced during TSA as the greatest contribution to the energy of the transverse magnetic anisotropy is provided by the nanocrystals in which one of the easy axes is oriented along the ribbon and stretched along the same axis. At the same time, the anisotropy of the ribbon shape is an important factor. Therefore, the magnetization vector in the nanocrystals predominantly oriented along the easy magnetization axis that is closer to the ribbon plane.

\section{Conclusion}

Summing up the results of X-ray diffraction and NGR-spectroscopy studies on the structure of the nanocrystals in soft magnetic alloys $\mathrm{Fe}_{87-X} \mathrm{Si}_{X} \mathrm{~B}_{9} \mathrm{Nb}_{3} \mathrm{Cu}_{1}(X=0-13.5)$ in the initial state, i.e. after quenching from the melt, after the nanocrystallization annealing and the tensile stress annealing, we can conclude that all the alloys in the initial state independently of the silicon concentration $(X)$ are in a state with an ultra fine grain (average grain size of about 2 $\mathrm{nm}$ ). Their structure is isotropic, it does not depend on the direction of observation (i.e., along or across the ribbon, or direction of the ribbon output upon quenching) and silicon content. After the nanocrystallization annealing, the intensity distribution in the diffraction patterns remains isotropic, but with increasing crystallite size up to 10-12 nm. A complete set of reflections, corresponding the bcc lattice of the alloy a-Fe (Si) becomes allowed. When the content of silicon $X=11$ and 13.5, in the diffraction patterns there appear superstructure peaks of the $\mathrm{D}_{3}$ phase $-\left(1 / 21 / 2 \frac{1}{1} / 2\right)$ and (100). After TSA along the direction of the tensile load application, there is an increase in the interplanar distances and the decrease in the transverse direction. The strain is anisotropic: within the accuracy of the experiment, no distortions in the $<111>$ directions are observed, and the distortions in the $<100>$ directions are maximum and reach $1 \%$. It is shown that the type (longitudinal or transverse) of the magnetic anisotropy depends on the sign (positive or negative) of the magnetoelastic coupling in nanocrystals, which, in turn, is determined by the contribution of the ordered phase $\mathrm{Fe}_{3} \mathrm{Si}$, characterized by a negative constant of magnetoelastic coupling.

For nanocrystalline alloy $\mathrm{Fe}_{87-X} \mathrm{Si}_{X} \mathrm{~B}_{9} \mathrm{Nb}_{3} \mathrm{Cu}_{1}$, a phenomenological model of the mechanism of inducing the longitudinal magnetic anisotropy at $X<9$ and the transverse magnetic anisotropy at $X>9$ due to the anisotropic distortions of nanocrystals was proposed.

\section{Acknowledgments}

This study was supported by the Russian Foundation for Basic Research (project no. 10-0200435) and by the Presidium of Russian Academy of Sciences (project no. 09-П-2-1035).

\section{References}

Bozorth, R.M. (1993). Ferromagnetism. IEEE Press, ISBN 0780310322, New York, USA

Bertotti, G., Fiorillo, F. (1994a). 7.1.2.2.1 Phase diagrams, lattice parameters and density, thermal expansion, In: Landolt-Bornstein. Numerical data and functional relationships in 
science and technology. New series. Group III: Solid state physics. V. 19. Magnetic properies of metals. Subv. i1. Magnetic alloys for technical applications. Soft magnetic alloys, invar and elinvar alloys, Wijn, H.P.J. (Ed.), pp. 35-44, Springer-Verlag, ISBN 3540555900/9783540555902/3-540-55590-0, Berlin, Germany, Retrieved from: http://www.springermaterials.com

Bertotti, G., Fiorillo, F. (1994b). 7.1.2.2.2 Elastic constants, mechanical properties, Ibid, Wijn, H.P.J. (Ed.), pp. 45-48, Springer-Verlag, ISBN 3540555900/9783540555902/3-54055590-0, Berlin, Germany, Retrieved from: http:/ / www.springermaterials.com

Bertotti, G., Fiorillo, F. (1994c). 7.1.2.3.3 Magnetostriction constants, Ibid, Wijn, H.P.J. (Ed.), pp. 55-58, Springer-Verlag, ISBN 3540555900/9783540555902/3-540-55590-0, Berlin, Germany, Retrieved from: http://www.springermaterials.com

Chernenkov, Yu.P., Ershov, N.V., Fedorov, V.I., Lukshina, V.A., \& Potapov, A.P. (2010). XRay diffraction studies of the structure of nanocrystals in $\mathrm{Fe}_{73.5} \mathrm{Si}_{13.5} \mathrm{~B}_{9} \mathrm{Nb}_{3} \mathrm{Cu}_{1}$ soft magnetic alloys before and after thermomechanical treatment. Phys. Solid State, Vol. 52, No. 3, (March, 2010), pp. 554-560, ISSN 1063-7834

Elsukov, E.P., Barinov, V.A., \& Konygin, G.N. (1989). The structural and magnetic parameters of the ordered Fe-Si alloys. Metallofizika, Vol. 11, No. 4, (April, 1989), pp. 52-59, ISSN 1024-1809 (in Russian)

Filippov, B.N. (2006). Theoretical and technological principles of production of soft magnetic materials with new level of functional properties, Proceeding of the Result Conference of Projects Leaders "New Materials and Structures", p 81, Moscow, Russia, November 30 - December 1, 2006 (in Russian)

Fischer, H., Barnes, A., \& Salmon, P. (2006). Neutron and x-ray diffraction studies of liquids and glasses. Rep. Prog. Phys., Vol. 69, No. 1, (January, 2006), pp. 233-299, ISSN 00344885

Glazer, A.A., Kleinerman, N.M., Lukshina, V.A., Potapov, A.P., \& Serikov, V.V. Thermomechanical treatment of the nanocrystalline alloy $\mathrm{Fe}_{73.5} \mathrm{Cu}_{1} \mathrm{Nb}_{3} \mathrm{Si}_{13.5} \mathrm{~B}_{9}$. Fiz. Met. Metalloved., No. 12, (January, 1991), pp. 56-61, ISSN 1812-7339 (in Russian)

Herzer, G. (1992). Nanocrystalline soft magnetic materials. J. Magn. Magn. Mater., Vol. 112, No.1-3, (July, 1992), pp. 258-262, ISSN 0304-8853

Herzer, G. (1994). Creep induced magnetic anisotropy in nanocrystalline Fe-Cu-Nb-Si-B alloys. IEEE Transactions on Magnetics, Vol. 30, No. 6, (June, 1994), pp. 4800-4802, ISSN 0018-9464

Hilfrich, K., Koelker, W., Petry, W., Schärpf, O., \& Nembach, E. (1994). The states of order and the phase diagram of $\mathrm{Fe}_{1-x} \mathrm{Si}_{\mathrm{x}}, 0.06 \leq \mathrm{x} \leq 0.20$, investigated by neutron scattering. Acta Metal. Mater. Vol. 42, No. 3, (March 1994), pp. 743-748, ISSN 09567151

Hofmann, B., \& Kronmüller, H. (1996) Stress-induced magnetic anisotropy in nanocrystalline FeCuNbSiB alloy. J. Magn. Magn. Mater, Vol. 152, No. 1-2, (January, 1996), pp. 91-98, ISSN 0304-8853

Kleinerman, N.M., Serikov, V.V., Lukshina, V.A., Potapov, A.P., \& Volkova, E.G. (2004). Induced magnetic anisotropy and the structure of nanocrystalline $\mathrm{Fe}-\mathrm{Co}-\mathrm{Cu}-\mathrm{Nb}-\mathrm{Si}$ B alloys with different content of Co: II structure of alloys with an induced magnetic anisotropy. Phys. Met. Metallogr., Vol. 107, No. 5, (May, 2004), pp. 449-456, ISSN 0031-918X

Litvinov, V.S., Karakishev, S.D. \& Ovchinnikov, V.V. (1982). Nuclear gamma-resonance spectroscopy of alloys, Metallurgiya, ISBN 5-1205068, Moscow, USSR (in Russian).

Lukshina, V.A., Dmitrieva, N.V., Noskova, N.I., Volkova, E.G., Kleinerman, N.M., Serikov, V.V., \& Potapov, A.P. (2002). Nanocrystalline alloy $\mathrm{Fe}_{73.5} \mathrm{Cu}_{1} \mathrm{Nb}_{3} \mathrm{Si}_{13.5} \mathrm{~B}_{9}$ : structure 
and magnetic properties. II. Thermal stability of induced magnetic anisotropy. Phys. Met. Metallogr., Vol. 93, No. 6, (June, 2002), pp. 536-543, ISSN 0031-918X

Noskova, N.I., Serikov, V.V., Glazer, A.A., Kleinerman, N.M., \&Potapov, A.P. (1992). Electron-microscopic investigation structure of $\mathrm{Fe}_{73.5} \mathrm{Cu}_{1} \mathrm{Nb}_{3} \mathrm{Si}_{13.5} \mathrm{~B}_{9}$ alloy in nanicrystalline state. Phys. Met. Metallogr. Vol. 74, No. 1. 1, (January, 1992), pp. 8086, ISSN 0031-918X

Ohnuma, M., Hono, K., Yanai, T., Fukunaga, H., \& Yoshizawa, Y. (2003). Direct evidence for structural origin of stress-induced magnetic anisotropy in $\mathrm{Fe}-\mathrm{Si}-\mathrm{B}-\mathrm{Nb}-\mathrm{Cu}$ nanocrystalline alloys. Appl. Phys. Lett., Vol. 83, No. 14, (September, 2003), pp. 28592861, ISSN 0003-6951

Ohnuma, M., Hono, K., Yanai, T., Nakano, M., Fukunaga, H., \& Yoshizawa, Y. (2005). Origin of the magnetic anisotropy induced by stress annealing in Fe-based nanocrystalline alloy. Appl. Phys. Lett., Vol. 86, No. 15, (April, 2005), 152513- 152511, ISSN $0003-$ 6951

Potapov, A.P., \& Filippov, B.N. (2009). Magnetic properties of soft magnetic nanocrystalline materials. Proceeding of $3^{\text {th }}$ All-Russian Conference on Nanomaterials, NANO-2009, pp. 41-43, ISBN 978-5-93667-123-5, Ekaterinburg, Russia, April 20-24, 2009 (in Russian)

Randrianantoandro, N., Gaffet, E., Mira, J. \& Greneche, J.-M. (1999). Magnetic hyperfine temperature dependence in Fe-Si crystalline alloys. Solid State Commun., Vol. 111, No. 6, (June, 1999), pp. 323-327, ISSN 0038-1098

Serikov, V.V., Kleinerman, N.M., Volkova, E.G., Lukshina, V.A., Potapov, A.P., \& Svalov, A.V. (2006). Structure and magnetic properties of nanocrystalline FeCuNbSiB alloys after a thermomechanical treatment. Phys. Met. Metallogr. Vol. 102, No. 3, (March, 2006), pp. 268-273, ISSN 0031-918X

Stearns, M.B. (1963). Internal magnetic fields, isomer shifts, and relative abundance of the various Fe sites in Fe-Si alloys. Phys.Rev., Vol. 129, No. 3, (March, 1963), pp. 11341144, ISSN 1098-0121

Warren, B.E. (1969). X-ray diffraction. Addison-Wesley, ISBN 0-486-66317-5, New York, USA

Wertheim, G.K. (1964). Mössbauer effect: Principles and applications. Academic Press, ISBN 1473662-1139, New York, USA

Yoshizawa, Y., Oguma, S., \& Yamauchi, K. J. (1988). New Fe-based soft magnetic alloys composed of ultrafine grain structure. J. Appl. Phys., Vol. 64, No. 10, (November, 1988), pp. 6044-6046, ISSN 0021-8979

Yoshizawa, Y. \& Yamauchi, K. (1989). Effects of magnetic field annealing on magnetic properties in ultrafine crystalline Fe-Cu-Nb-Si-B alloys. IEEE Trans. Magn., Vol. 25, No. 5, (September, 1989), pp. 3324-3326, ISSN 0018-9464

Yoshizawa, Y. (2006). Nanocrystalline Soft Magnetic Materials and Their Applications, In: Handbook of advanced magnetic materials. Vol. 4: Properties and applications, Liu, Yi, Sellmyer, D. J., Shindopp D., pp. 124-158, Shpringer, ISBN 1-4020-7983-4, New York, USA 


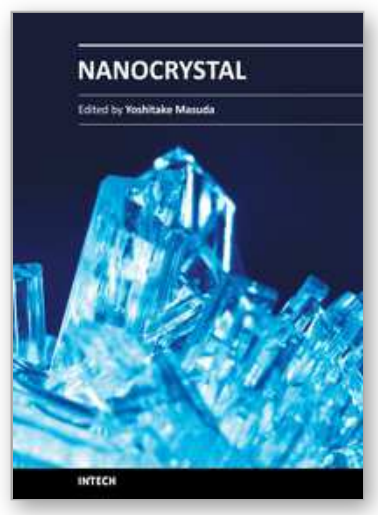

\author{
Nanocrystal \\ Edited by Dr. Yoshitake Masuda
}

ISBN 978-953-307-199-2

Hard cover, 494 pages

Publisher InTech

Published online 28, June, 2011

Published in print edition June, 2011

We focused on cutting-edge science and technology of Nanocrystals in this book. â€œNanocrystalâ€ is expected to lead to the creation of new materials with revolutionary properties and functions. It will open up fresh possibilities for the solution to the environmental problems and energy problems. We wish that this book contributes to bequeath a beautiful environment and valuable resources to subsequent generations.

\title{
How to reference
}

In order to correctly reference this scholarly work, feel free to copy and paste the following:

Nikolay V. Ershov, Yuri P. Chernenkov, Vladimir I. Fedorov, Vera A. Lukshina, Nadezda M. Kleinerman, Vadim V. Serikov, Anatoly P. Potapov and Nikita K. Yurchenko (2011). Structure of Nanocrystals in Finemets with Different Silicon Content and Stress-Induced Magnetic Anisotropy, Nanocrystal, Dr. Yoshitake Masuda (Ed.), ISBN: 978-953-307-199-2, InTech, Available from: http://www.intechopen.com/books/nanocrystal/structure-ofnanocrystals-in-finemets-with-different-silicon-content-and-stress-induced-magnetic-ani

\section{INTECH}

open science | open minds

\section{InTech Europe}

University Campus STeP Ri

Slavka Krautzeka 83/A

51000 Rijeka, Croatia

Phone: +385 (51) 770447

Fax: +385 (51) 686166

www.intechopen.com

\section{InTech China}

Unit 405, Office Block, Hotel Equatorial Shanghai

No.65, Yan An Road (West), Shanghai, 200040, China 中国上海市延安西路65号上海国际贵都大饭店办公楼 405 单元 Phone: $+86-21-62489820$

Fax: +86-21-62489821 
(C) 2011 The Author(s). Licensee IntechOpen. This chapter is distributed under the terms of the Creative Commons Attribution-NonCommercialShareAlike-3.0 License, which permits use, distribution and reproduction for non-commercial purposes, provided the original is properly cited and derivative works building on this content are distributed under the same license. 